\title{
Composition and variability of the essential oils of the leaves and berries from Juniperus navicularis
}

\author{
C. Cavaleiro ${ }^{a, *}$, L.R. Salgueiro ${ }^{\text {a }}$, A.P. da Cunha ${ }^{a}$, \\ A.C. Figueiredo ${ }^{\text {b }}$, J.G. Barroso ${ }^{\text {b }}$, A. Bighelli ${ }^{\text {c }}$, J. Casanova ${ }^{c}$ \\ a Faculdade de Farmácia C.E.F., Laboratório de Farmacognosia, Universidade de Coimbra, Rua do \\ Norte, 3000 Coimbra, Portugal \\ b Faculdade de Ciências, Departamento de Biologia Vegetal, Centro de Biotecnologia Vegetal, \\ Universidade de Lisboa Campo Grande, Bloco C2, 1479-016 Lisbon, Portugal \\ c Université de Corse, Equipe Chimie et Biomasse, UMR CNRS 6134, Route des Sanguinaires, 20000 \\ Ajaccio, France
}

Received 2 April 2001; accepted 8 February 2002

\begin{abstract}
The compositions of the essential oils isolated from leaves and berries of Juniperus navicularis Gand., an endemic species from Portugal, were investigated by GC and GC-MS. Oils from representative samples of populations as well as from individual samples were studied. The oils consisted mainly of monoterpene hydrocarbons $(67.1-88.0 \%$ and $61.7 \%$ for leaf and berry oils, respectively). $\alpha$-Pinene (6.3-38.0\%), limonene (7.0-34.6\%), $\alpha$-phellandrene $(2.2-13.1 \%)$ and $p$ cymene (4.8-10.3\%) were the major constituents of the oils from leaves and $\beta$-myrcene $(25.8 \%)$ and $\alpha$-pinene $(24.4 \%)$ the major ones of the oil from berries. No meaningful differences were observed comparing the composition of leaf oils from populations collected at distinct seasons but, within the same season, the range of variation of the major components suggests variability. Hierarchical clustering and principal component analysis (PCA) of the compositional data of the oils from individual samples confirms the variability allowing to establish two groups of essential oils differentiated by the content of the major constituents ( $\alpha$-pinene, limonene, $\alpha$-phellandrene and $E$-nerolidol) and the ratios $\alpha$-pinene/limonene.
\end{abstract}

(C) 2002 Elsevier Science Ltd. All rights reserved.

Keywords: Juniperus navicularis; Cupressaceae; Essential oil; Leaves; Berries; Chemical variability; GC/MS; ${ }^{13} \mathrm{C}$ NMR

* Corresponding author. Tel.: +351-239-859-995; fax: +351-239-827-126.

E-mail address: cavaleir@ff.uc.pt (C. Cavaleiro). 


\section{Introduction}

Juniperus navicularis Gand. (=J. oxycedrus L. ssp. transtagana Franco) is an endemic species from Portugal where it is known as 'piorro', that grows in restricted regions of the center-west and southwest littoral of Portugal at low altitudes (0-80 $\mathrm{m}$ ) in maritime sandy sites, usually inside pinewoods and scrubs (Franco, 1986; Costa et al., 1993). Juniperus navicularis is a shrub up to $2 \mathrm{~m}$ high, usually bushy, with leaves 4-12 $41-1.5 \mathrm{~mm}$, spreading; berry-like $7-10 \mathrm{~mm}$ globose, green at first, latter reddish to yellowish. At present it has become scattered and is rare.

Cavaleiro et al. (1997) and Adams (1998, 2000) have reported the compositions of the oils isolated from leaves. These oils were dominated by monoterpene hydrocarbons (70.3-90.2\%), limonene and $\alpha$-pinene being the main constituents. In both studies only a small number of samples, of $J$. navicularis, were analyzed. Moreover, no reports were found about the composition of the berry oils.

\section{Materials and methods}

\subsection{Plant material and essential oil isolation}

Representative samples of leaves from four populations were collected in October at important sites of distribution of J. navicularis (Fig. 1): Apostiça (sample A), Figueira da Foz (sample B), Vale do Guizo (sample C) and Pinhal de Arez (sample D). Additionally, representative samples of leaves from two of the before mentioned populations were collected at different seasons: Figueira da Foz (sample B1, collected in January) and Vale do Guizo (sample C1, collected in July). In order to study the variability of the essential oils, 45 isolated plants were also picked from the same place at the same time as homogeneous samples of the corresponding populations: Figueira da Foz-B (samples 1-13), Vale do Guizo-C (samples 14-20), Pinhal de Arez-D (samples 21-38) and Figueira da Foz-B1 (samples 39-45).

One sample of ripe berries (sample E) was collected in October from the population of Vale do Guizo, the only population showing fructification.

Voucher specimens were deposited in the herbarium of the Instituto Botânico of the University of Coimbra (COI): C. Cavaleiro 215-216, Apostiça; C. Cavaleiro 259-261, Figueira da Foz; C. Cavaleiro 435-436, 454-455, Vale do Guizo; C. Cavaleiro 463-464, Pinhal de Arez.

For essential oils isolation and yield determination, fresh material was submitted to water distillation for $3 \mathrm{~h}$ using a Clevenger-type apparatus according to the European Pharmacopoeia (1997). Berries were crushed prior to the water distillation.

\subsection{Essential oil analysis}

The essential oils were analyzed by GC and GC-MS. For GC analyses two fused silica capillary columns with different stationary phases were used: SPB-1 


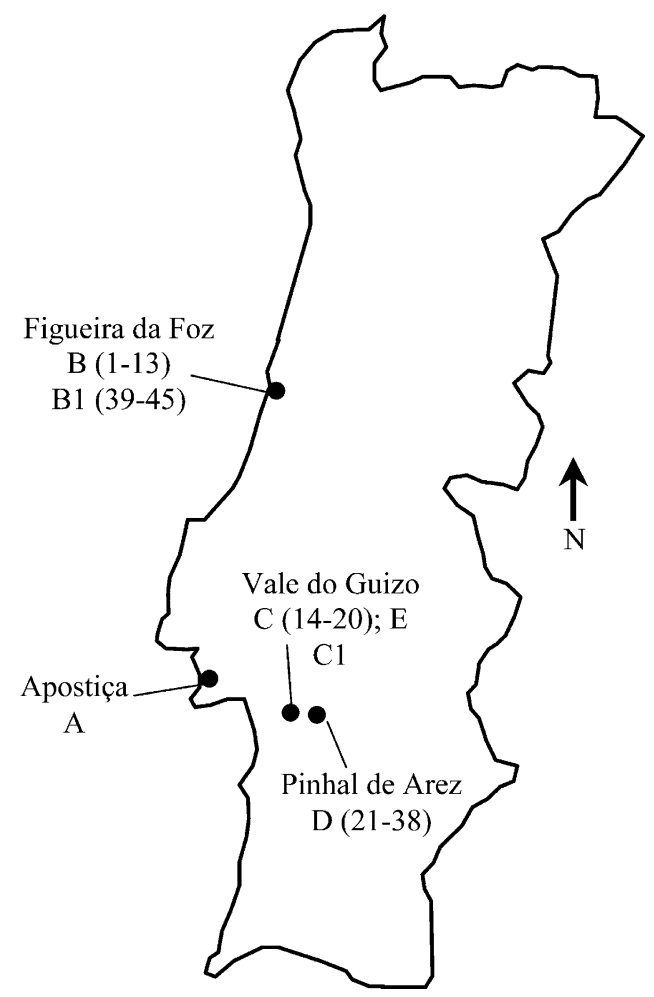

Fig. 1. Sampling of J. navicularis from Portugal.

(polydimethylsiloxane $30 \mathrm{~m} \times 0.20 \mathrm{~mm}$ i.d., film thickness $0.20 \mu \mathrm{m}$ ), and SupelcoWax 10 (polyethyleneglycol $30 \mathrm{~m} \times 0.20 \mathrm{~mm}$ i.d., film thickness $0.20 \mu \mathrm{m}$ ). Oven temperature program: $70-220{ }^{\circ} \mathrm{C}\left(3{ }^{\circ} \mathrm{C} / \mathrm{min}\right), 220^{\circ} \mathrm{C}(15 \mathrm{~min})$; injector and detector temperature: $250{ }^{\circ} \mathrm{C}$; carrier gas: helium, adjusted to a linear velocity of $30 \mathrm{~m} / \mathrm{s}$; splitting ratio 1:40.

GC-MS was performed with a HP1 fused silica column (polydimethylsiloxane $30 \mathrm{~m} \times 0.25 \mathrm{~mm}$ i.d., film thickness $0.25 \mu \mathrm{m}$ ), interfaced with a mass selective detector. GC parameters as above; interface temperature: $250{ }^{\circ} \mathrm{C}$; MS source temperature: $230{ }^{\circ} \mathrm{C}$; MS quadrupole temperature: $150{ }^{\circ} \mathrm{C}$; ionization energy: $70 \mathrm{eV}$; ionization current: $60 \mu \mathrm{A}$; scan range: $35-350 \mathrm{u}$; scans/s: 4.51 .

The oil components were identified by their retention indices, calculated by linear interpolation relative to retention times of a series of $n$-alkanes, and by comparison of their mass spectra, with those of an home-made library and of the literature (Adams, 1995; Joulain and König, 1998). Major compounds were also identified by ${ }^{13} \mathrm{C}-\mathrm{NMR}$. The identification was performed by computer-aided analysis of the ${ }^{13} \mathrm{C}$ NMR spectrum of the total oil, by comparing the signals obtained with those of pure compounds included in a library created in our laboratory (Tomi et al., 1995; Rezzi et al., 2001). This ${ }^{13} \mathrm{C}-\mathrm{NMR}$ technique has proved to be useful for the identification 
of ambiguous components which are poorly separated by GC or insufficiently elucidated by mass spectra and retention indices.

Relative amounts of individual components were calculated from the GC peak areas without FID response correction factor.

\subsection{Data analysis}

The compositional data of 45 investigated samples of J. navicularis were submitted to multivariate statistic analysis accomplished by SPSS 10.0 (Superior Performing Software Systems, Inc.). Only constituents in a concentration higher than $1.0 \%$ were used as variables for analysis.

Data were subject to a hierarchical clustering using average linkage with square Euclidean distance measure and factor analysis using the principal components extraction method (PCA). The aptitude of the complete correlation matrix was checked by the Kaiser Meyer-Olkin criterion $(\mathrm{KMO}=0.563)$. After PCA, another hierarchical clustering concerning the two extracted principal components was performed.

\section{Results and discussion}

The essential oils isolated from leaves were obtained in a yield ranging from 0.4 to $0.7 \%(\mathrm{v} / \mathrm{w})$ for leaves and $0.5 \%$ for berries. Qualitative and quantitative data are shown in Table 1. Forty-three to 64 compounds were identified accounting for 92.6$98.3 \%$ of the total oils.

The oils from both leaves and berries, were dominated by monoterpene hydrocarbons $(67.1-88.0 \%$ and $61.7 \%$ respectively). $\alpha$-Pinene $(6.3-38.0 \%)$, limonene (7.0-34.6\%), $\alpha$-phellandrene $(2.2-13.1 \%)$ and $p$-cymene $(4.8-10.3 \%)$ were the major compounds of this fraction in the leaf oils whereas $\beta$-myrcene $(25.8 \%)$ and $\alpha$-pinene $(24.4 \%)$ were the major ones in that of the berry oil. The oxygen-containing monoterpene fraction represented $3.6-10.4 \%$ of the total oils from leaves while in the berry oil this fraction attained only $1.3 \%$. The sesquiterpene compounds represented 5.3$20.3 \%$ of the total leaf oils. Although some of these components showed quantitative variations, $E$-nerolidol showed the most markable one $(0.1-8.0 \%)$. In the berry oil, the sesquiterpene fraction attained $30.7 \%$, germacrene $\mathrm{D}(8.5 \%)$ and $\delta$-cadinene $(5.5 \%)$ being its main compounds.

No meaningful differences were recorded in the composition of the oils of the same population isolated from leaves collected at different periods of the year. In contrast, concentration of the major compounds varied to some extent in the oil samples of the different populations collected during the same season, suggesting some degree of variability. This was confirmed by the analysis of the oil samples obtained from individual plants. The hierarchical clustering phenogram, based in the original variables (Fig. 2), grouped the 45 samples of J. navicularis into two significant clusters (clusters I, II). PCA reduced the 35 variables to three principal components representing $97.3 \%$ of the total variance; $\alpha$-pinene, limonene, $\alpha$-phellandrene 
Table 1

Percentage composition of the essential oils of populations of J. navicularis

\begin{tabular}{|c|c|c|c|c|c|c|c|c|}
\hline \multirow[t]{2}{*}{$\mathrm{RI}^{\mathrm{a}}$} & \multirow[t]{2}{*}{ Compound } & \multicolumn{6}{|c|}{ Leaf oils } & \multirow{2}{*}{$\begin{array}{l}\text { Berry } \\
\text { oil } \\
\text { E }\end{array}$} \\
\hline & & A & B & B1 & $\mathrm{C}$ & $\mathrm{C} 1$ & $\mathrm{D}$ & \\
\hline 922 & $\alpha$-Thujene & 0.9 & 0.3 & 0.3 & 0.5 & 0.5 & 0.2 & $\mathrm{t}$ \\
\hline 930 & $\alpha$-Pinene & 24.0 & 8.7 & 6.3 & 17.8 & 15.0 & 38.0 & 24.4 \\
\hline 942 & Verbenene & & & & $\mathrm{t}$ & $\mathrm{t}$ & 0.2 & \\
\hline 943 & Camphene & 0.4 & 0.2 & 0.1 & 0.4 & 0.4 & 0.4 & 0.4 \\
\hline 964 & Sabinene & 3.2 & 2.3 & 1.4 & 0.7 & 1.5 & 0.6 & 0.4 \\
\hline 970 & $\beta$-Pinene & 3.0 & 2.7 & 1.4 & 2.1 & 2.2 & 2.4 & 3.3 \\
\hline 980 & $\beta$-Myrcene & 6.1 & 5.3 & 4.1 & 7.9 & 8.0 & 5.4 & 25.8 \\
\hline 997 & $\alpha$-Phellandrene & 9.8 & 11.8 & 10.9 & 7.8 & 13.1 & 2.2 & 0.3 \\
\hline 998 & $\Delta$-2-Carene & 1.1 & 0.7 & 0.3 & 0.3 & 0.3 & 1.0 & 0.1 \\
\hline 1005 & $\Delta$-3-Carene & 0.8 & 0.3 & 0.1 & 0.1 & 0.1 & 0.4 & 0.1 \\
\hline 1010 & $\alpha$-Terpinene & 0.5 & 0.5 & 0.4 & 0.6 & 0.7 & 0.1 & 0.1 \\
\hline 1011 & $p$-Cymene & 7.8 & 6.3 & 5.3 & 10.3 & 5.4 & 4.8 & 0.1 \\
\hline 1020 & $\beta$-Phellandrene ${ }^{\mathrm{b}}$ & 5.4 & 4.6 & 4.4 & 4.3 & 4.8 & 2.5 & 1.8 \\
\hline 1020 & Limonene $^{\mathrm{b}}$ & 20.2 & 34.6 & 27.6 & 21.5 & 22.7 & 7.0 & 3.6 \\
\hline 1035 & $E$ - $\beta$-Ocimene & 0.2 & 1.0 & 1.1 & 0.1 & 0.1 & 0.5 & \\
\hline 1046 & $\gamma$-Terpinene & 0.9 & 0.8 & 0.6 & 0.7 & 0.9 & 0.1 & 0.2 \\
\hline 1051 & cis-Sabinene hydrate & & & 0.1 & 0.1 & 0.1 & & \\
\hline 1071 & 2,5-Dimethylstyrene & 0.1 & 0.1 & 0.1 & 0.1 & 0.2 & 0.2 & \\
\hline 1077 & Terpinolene & 3.6 & 4.2 & 3.9 & 2.8 & 4.4 & 1.1 & 1.1 \\
\hline 1082 & Linalool & 0.3 & $\mathrm{t}$ & 0.1 & 0.8 & 0.8 & 0.3 & \\
\hline 1098 & Fenchol & & & & 0.1 & 0.1 & & \\
\hline 1104 & $\alpha$-Campholenal & 0.1 & & 0.1 & & & 0.1 & \\
\hline 1106 & cis-p-2-Menthen-1-ol & 0.1 & 0.2 & 0.1 & 0.1 & 0.1 & 0.1 & \\
\hline 1120 & trans-p-2-Menthen-1-ol & & & 0.1 & & & 0.1 & \\
\hline 1145 & Isoborneol & & & 0.1 & & & 0.4 & \\
\hline 1149 & Borneol & 0.2 & 0.2 & & 0.3 & 0.5 & 0.2 & 0.1 \\
\hline 1158 & $p$-Cymene-8-ol & 0.2 & 0.2 & 0.1 & 0.4 & 0.2 & 0.5 & \\
\hline 1158 & Terpinen-4-ol & 1.4 & 1.6 & 1.6 & 2.2 & 2.2 & 0.7 & 0.3 \\
\hline 1169 & $\alpha$-Terpineol & 1.1 & 1.2 & 0.9 & 2.5 & 2.6 & 1.6 & 0.2 \\
\hline 1176 & Myrtenol & & & 0.2 & 0.3 & & 0.1 & \\
\hline 1195 & cis-Carveol & & & 0.1 & 0.1 & $\mathrm{t}$ & 0.2 & \\
\hline 1210 & Citronellol & & & 0.1 & 0.2 & 0.1 & & \\
\hline 1211 & Cuminaldehyde & & & & & & 0.1 & \\
\hline 1214 & Neral & & & & & & 0.4 & \\
\hline 1214 & Methyl thymyl oxide & & & 0.2 & 0.4 & 0.2 & 0.1 & \\
\hline 1238 & Decen-1-ol & 0.4 & 1.0 & 1.0 & 0.5 & 0.4 & 0.4 & \\
\hline 1267 & Bornyl acetate & & 0.1 & & 0.2 & 0.2 & 0.3 & 0.4 \\
\hline 1275 & Carvacrol & & & 0.2 & & 0.1 & 0.1 & \\
\hline 1328 & $\alpha$-Terpinyl acetate & 0.2 & 1.3 & 1.9 & 2.6 & 2.6 & 0.3 & \\
\hline 1331 & Citronellyl acetate & & & 0.5 & & & 0.1 & 0.2 \\
\hline 1342 & $\alpha$-Cubebene & $\mathrm{t}$ & $\mathrm{t}$ & & 0.1 & 0.1 & 0.1 & 0.3 \\
\hline 1359 & Geranyl acetate & & & & 0.1 & $\mathrm{t}$ & & 0.1 \\
\hline 1369 & $\alpha$-Copaene & 0.1 & 0.4 & 0.2 & 0.2 & 0.3 & 0.3 & 0.2 \\
\hline 1380 & $\beta$-Cubebene & & $\mathrm{t}$ & & & $\mathrm{t}$ & & \\
\hline 1382 & $\beta$-Elemene & $\mathrm{t}$ & 0.1 & 0.1 & 0.1 & $\mathrm{t}$ & 0.1 & 0.2 \\
\hline
\end{tabular}


Table 1 (continued)

\begin{tabular}{|c|c|c|c|c|c|c|c|c|}
\hline \multirow[t]{2}{*}{$\mathrm{RI}^{\mathrm{a}}$} & \multirow[t]{2}{*}{ Compound } & \multicolumn{6}{|c|}{ Leaf oils } & \multirow{2}{*}{$\begin{array}{l}\text { Berry } \\
\text { oil } \\
\text { E }\end{array}$} \\
\hline & & A & B & B1 & $\mathrm{C}$ & $\mathrm{C} 1$ & $\mathrm{D}$ & \\
\hline 1408 & E-Caryophyllene & 0.5 & 0.5 & 0.8 & 0.3 & 0.3 & 0.5 & 1.5 \\
\hline 1442 & $\alpha$-Humulene & 0.2 & 0.3 & 0.4 & 0.2 & 0.2 & 0.2 & 0.9 \\
\hline 1447 & trans- $\beta$-Farnesene & 0.1 & & 0.1 & $\mathrm{t}$ & $\mathrm{t}$ & 0.1 & 0.6 \\
\hline 1462 & $\gamma$-Muurolene & 0.1 & 0.1 & 0.3 & 0.2 & 0.2 & 0.2 & 0.5 \\
\hline 1467 & Germacrene D & 0.2 & 0.1 & 0.2 & 0.5 & 0.6 & 0.4 & 8.5 \\
\hline 1472 & $\beta$-Selinene & $\mathrm{t}$ & 0.1 & 0.4 & & $\mathrm{t}$ & & \\
\hline 1486 & $\alpha$-Muurolene & 0.4 & 0.4 & & 0.3 & 0.3 & 0.4 & 1.1 \\
\hline 1497 & $\beta$-Bisabolene & 0.3 & 0.3 & 0.1 & 0.1 & 0.3 & 0.8 & \\
\hline 1498 & $\gamma$-Cadinene & 0.7 & 0.5 & & 0.4 & 0.4 & 1.1 & 1.6 \\
\hline 1502 & cis-Calamelene & & & & $\mathrm{t}$ & 0.1 & 0.2 & \\
\hline 1508 & $\delta$-Cadinene & 0.8 & 1.3 & 2.4 & 0.9 & 1.1 & 1.5 & 5.5 \\
\hline 1515 & Cadina-1,4-diene & & & 0.3 & & & 0.3 & 0.1 \\
\hline 1521 & $\alpha$-Cadinene & 0.2 & & 0.1 & 0.1 & 0.2 & 0.1 & 0.2 \\
\hline 1526 & Elemol & 0.1 & 0.1 & 0.3 & & & 0.3 & 0.2 \\
\hline 1540 & Germacrene B & 0.1 & 0.8 & 1.3 & 0.1 & 0.1 & 0.3 & 0.3 \\
\hline 1545 & $E$-Nerolidol & 1.2 & 0.3 & 0.2 & 0.1 & 0.1 & 8.0 & 2.3 \\
\hline 1557 & Caryophyllene oxide & & 0.3 & & 0.1 & 0.1 & & \\
\hline 1575 & Cedrol & & & 0.3 & 0.1 & $\mathrm{t}$ & 0.1 & \\
\hline 1582 & Humulene oxide & & 0.1 & & 0.1 & 0.1 & & \\
\hline 1607 & $\gamma$-Eudesmol & & $\mathrm{t}$ & & 0.1 & & & \\
\hline 1616 & T-Cadinol & 0.4 & 0.9 & 2.1 & 0.4 & 0.3 & 1.1 & 2.3 \\
\hline 1627 & T-Muurorol & 0.1 & 0.3 & 1.2 & 0.5 & 0.5 & 0.6 & 0.7 \\
\hline 1628 & $\alpha$-Cadinol & 0.2 & 0.5 & 2.9 & & & 1.3 & 3.0 \\
\hline 1659 & $\alpha$-Bisabolol & & 0.7 & 2.6 & $\mathrm{t}$ & & 2.2 & 0.7 \\
\hline 1695 & Farnesol $^{\mathrm{c}}$ & & & 0.2 & 0.7 & & 0.1 & \\
\hline 1941 & Sandaracopimaradiene & & & & & & 0.1 & 0.3 \\
\hline 1964 & Manoyl oxide & $\mathrm{t}$ & $\mathrm{t}$ & 0.3 & 0.2 & 0.1 & 0.3 & \\
\hline 1969 & Isopimaradiene & & & & & 0.1 & 0.2 & 0.7 \\
\hline 2018 & Abietatriene & $\mathrm{t}$ & & 0.1 & & & & \\
\hline $\begin{array}{l}\text { Monoterpene } \\
\text { hydrocarbons }\end{array}$ & & 88.0 & 84.4 & 78.0 & 68.3 & 67.3 & 80.3 & 61.7 \\
\hline $\begin{array}{l}\text { Oxygen } \\
\text { containing } \\
\text { monoterpenes }\end{array}$ & & 3.6 & 4.8 & 10.4 & 6.4 & 5.7 & 9.8 & 1.3 \\
\hline $\begin{array}{l}\text { Sesquiterpene } \\
\text { hydrocarbons }\end{array}$ & & 3.7 & 4.9 & 3.5 & 6.7 & 6.6 & 4.2 & 21.5 \\
\hline $\begin{array}{l}\text { Oxygen } \\
\text { containing }\end{array}$ & & 2.0 & 3.2 & 2.1 & 9.8 & 13.7 & 1.1 & 9.2 \\
\hline sesquiterpenes & & & & & & & & \\
\hline Other & & 0.4 & 1.0 & 0.7 & 1.4 & 1.0 & 0.6 & 1.0 \\
\hline Total identified & & 97.7 & 98.3 & 94.7 & 92.6 & 94.1 & 96.0 & 94.7 \\
\hline
\end{tabular}

$\mathrm{t}$ : traces $(<0.05 \%)$.Samples collected in October-A (Apostiça), B (Figueira da Foz), C (Vale do Guizo) and D (Pinhal de Arez); sample collected in January-B1 (Figueira da Foz); sample collected in July-C1 (Vale do Guizo). Sample of ripe berries-E (Vale do Guizo).

a Retention index on the SPB-1 column.

b Quantitative determination on SupelcoWax column.

${ }^{\mathrm{c}}$ Correct isomer not determined. 


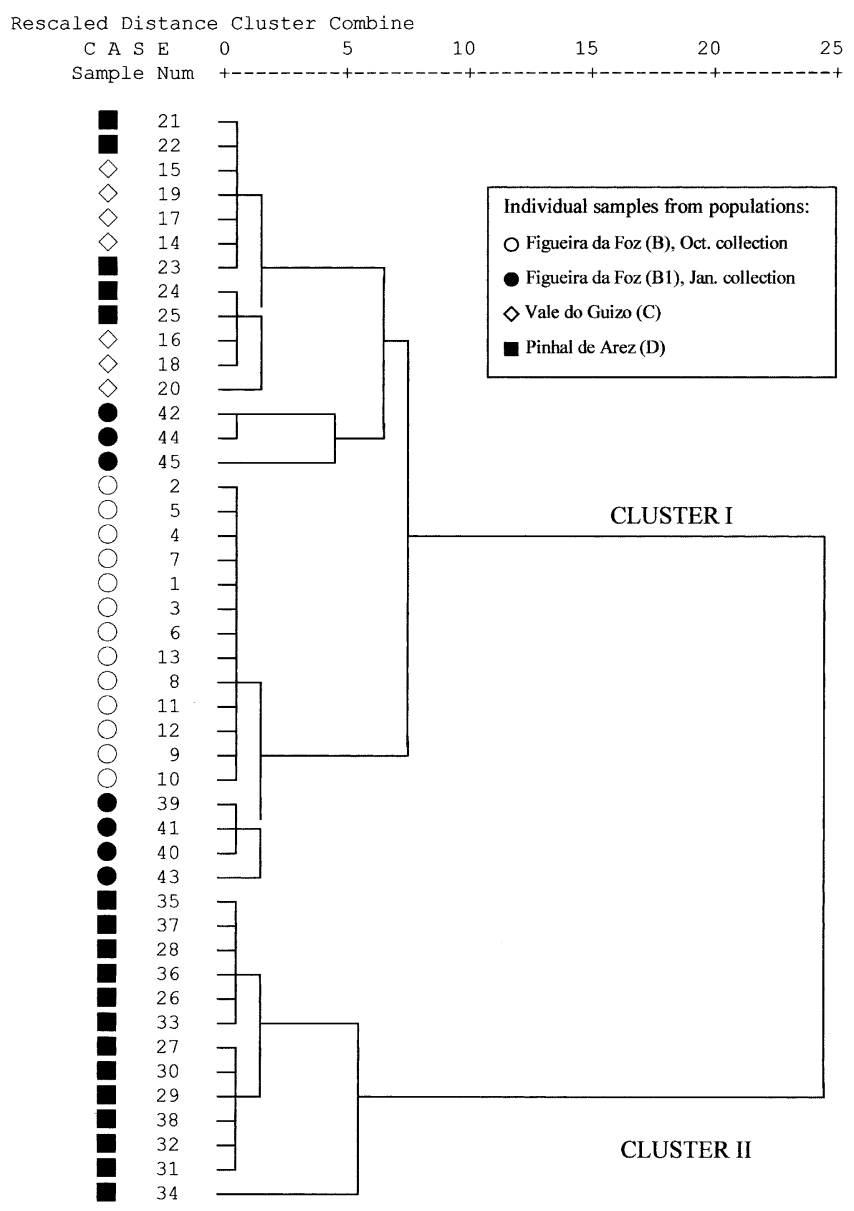

Fig. 2. Phenogram from the hierarchical cluster analysis of the individual samples of $J$. navicularis based in the original variables.

and $E$-nerolidol showed the highest coefficient factors. The hierarchical classification relative to the two extracted components confirmed the clustering based in the original variables.

PCA and the hierarchical classifications (Fig. 3) allowed to recognize two distinct essential oil types based on the content of $\alpha$-pinene, limonene, $\alpha$-phellandrene and E-nerolidol.

The oils of cluster I (71\% of the samples) are characterized by $\alpha$-pinene (average $=11.4 \%, \mathrm{SD}=5.5$ ), limonene (average $=28.0 \%, \mathrm{SD}=6.6$ ), $\alpha$-phellandrene (average $=6.7 \%, \mathrm{SD}=5.6$ ) and $E$-nerolidol (average $=0.2 \%, \mathrm{SD}=0.2$ ); the $\alpha$-pinene/limonene ratio being close to 1:2. The essential oils of cluster II (29\% of the samples) are characterized by $\alpha$-pinene (average $=37.0 \%, \mathrm{SD}=5.6$ ), limonene $($ average $=6.8 \%, \mathrm{SD}=0.4), \alpha$-phellandrene $($ average $=1.5 \%, \mathrm{SD}=1.3)$ and 


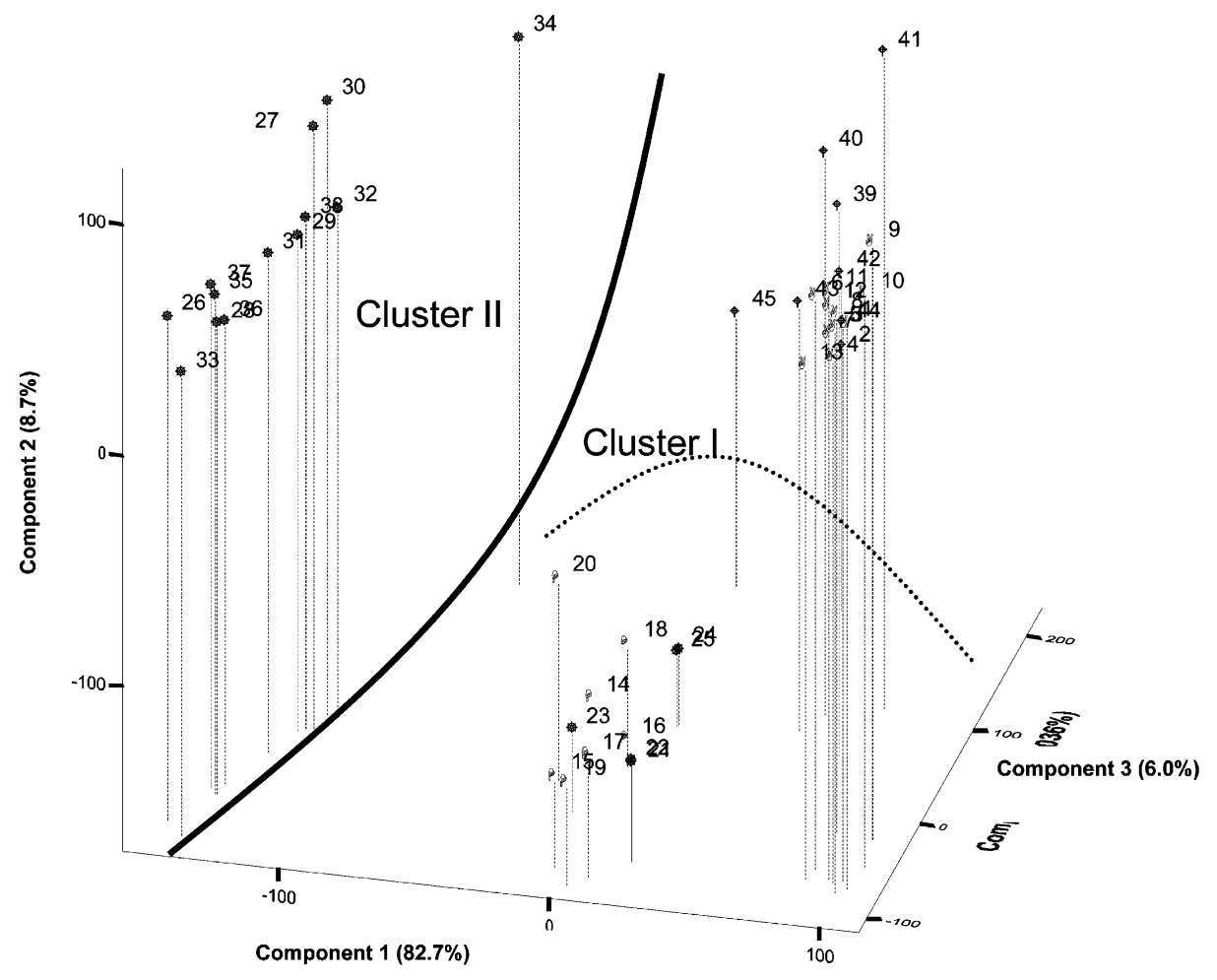

Individual samples from populations:

Figueira da Foz (B) Oct. collection; Figueira da Foz (B1) Jan. collection; ${ }^{\circledR}$ Vale do Guizo (C); Pinhal de Arez (D)

Fig. 3. Scatterplot of the 45 individual samples for the three principal components extracted in PCA.

$E$-nerolidol (average $=8.7 \%, \mathrm{SD}=1.6$ ); the $\alpha$-pinene/limonene ratio being close to $6: 1$.

All samples from Vale do Guizo (C) and Figueira da Foz (B and B1) were grouped in cluster I. However, within this cluster, two subgroups are well defined (Fig. 2): one with plants from Figueira Foz, whatever the collecting season (October-B and January-B1) and the other one with all the plants from Vale do Guizo (C) and some (28\%) from Pinhal de Arez (D). The oils of these subgroups showed distinct compositions, in what concerns to the percentages of limonene $(31.1 \pm 6.1 \%$ vs. $22.8 \pm 3.7 \%)$, $\alpha$-pinene $(7.5 \pm 1.9 \%$ vs. $17.8 \pm 2.9 \%)$, $\alpha$-phellandrene $(10.2 \pm 3.9 \%$ vs. $0.7 \pm 0.6 \%)$ and $p$-cymene $(5.9 \pm 0.6 \%$ vs. $13.5 \pm 1.0 \%)$. In agreement with the results of the collective samples it seems that the seasonal conditions have not a great influence in the oil composition.

Plants from Pinhal de Arez (D) were grouped in both clusters (28\% in cluster I and $72 \%$ in cluster II), which seems to indicate that this variability may be due to genetic factors. 


\section{Acknowledgments}

We thank to Dr Armando Moura and Eng. Constança Gomes (DRAAl) for their invaluable help in prospecting and plant collection, to Prof Jorge Paiva for botanic identifications. Thanks are also due to JNICT (Portugal) for financial support (PBIC/BIA1995) and to ICCTI (Portugal) and CNRS (France) for travel grants.

\section{References}

Adams, R.P., 1995. Identification of Essential Oil Components by Gas Chromatography/Mass Spectroscopy. Allured Publishing Corporation, Carol Stream, Illinois USA.

Adams, R.P., 1998. The leaf essential oils and chemotaxonomy of Juniperus sect. Juniperus. Biochem. Syst. Ecol. 26, 637-645.

Adams, R.P., 2000. Systematic of Juniperus section Juniperus based on leaf essential oils and random amplified polymorphic DNAs (RAPDs). Biochem. Syst. Ecol. 28, 515-528.

Cavaleiro, C., Salgueiro, L.R., Figueiredo, A.C., Barroso, J.G., Poença da Cunha, A., 1997. Composition of the essential oil from leaves of Juniperus navicularis grown in Portugal. 28th International Symposium on Essential Oils, Eskisehir, Turkey, September, 1997 abst. book, 22.

Costa, J.C., Capelo, J.H., Lousã, M.F., Aguiar, C., 1993. Comunautés de Juniperus au Portugal. Colloques Phytosociologiques 12, 499-526.

Council of Europe, 1997, European Pharmacopoeia, 3th ed. Strasbourg, pp. 121-122.

Franco, J.A., 1986. Juniperus L. In: Castroviejo, S., Laínz, M., López-González, G., Montserrat, P., Muñoz-Garmendia, F., Paiva, J., Villar, L. (Eds.), Flora Iberica, vol. I. Real Jardín Botánico, CSIC, Madrid, pp. 181-188.

Joulain, D., König, W.A., 1998. The Atlas of Spectral Data of Sesquiterpene Hydrocarbons. EB-Verlag, Hamburg.

Rezzi, S., Cavaleiro, C., Bighelli, A., Salgueiro, L., Proença da Cunha, A., Casanova, J., 2001. Intraspecific variability of the leaf essential oil of Juniperus phoenicea subsp. turbinata from Corsica. Biochem. Syst. Ecol. 29, 179-188.

Tomi, F., Bradesi, P., Bighelli, A., Casanova, J., 1995. Computer-aided identification of individual components of essential oils using carbon-13 NMR spectroscopy. J. Magn. Reson. Anal. 1, 25-34. 